\title{
A rare case of hypoglycemia induced by a classic gastrointestinal stromal tumor
}

\author{
Sorab Gupta, MD, ${ }^{a}$ Vaani Mehta, MD, ${ }^{\mathrm{b}}$ Shradha Ahuja, MD, ${ }^{a}$ Meenakshi Punj, MD, ${ }^{a}$ \\ Oscar Carazas, MD, and Massoud Kazzi, MD ${ }^{\mathrm{c}}$
}

${ }^{a}$ Department of Internal Medicine, St Barnabas Hospital, Bronx, New York; ${ }^{b}$ Department of Obstetrics and Gynecology, Government Medical College and Hospital, Chandigarh, India; and 'Department of Critical Care, St Barnabas Hospital, Bronx, New York

$\mathrm{H}$ ypoglycemia, a frequently encountered medical emergency, is usually seen in patients with diabetes, most commonly as a result of iatrogenesis. However, it can also be encountered in nondiabetic patients. Various causes, such as pancreatic islet cell tumors producing insulin, primary or secondary adrenal insufficiency, advanced liver disease, pheochromocytoma and hypothyroidism, have been found to contribute to the condition in the nondiabetic population. ${ }^{1}$ In rare cases, an excessive production of insulin-like growth factor (IGF-2) - a condition known as nonislet cell tumor-induced hypoglycemia (NICTH) - has also been found to cause hypoglycemia. Hypoinsulinemic hypoglycemia, with low IGF-1 levels and an IGF$2-\mathrm{IgF} 1$ ratio of greater than 10 , is found to be suggestive of NICTH.

\section{Case presentation and summary}

An 81-year-old man with a history of diabetes mellitus, systolic heart failure, chronic kidney disease, and metastatic classical gastrointestinal spindle cell sarcoma presented to the emergency department with an acute change in mental status resulting from a new onset hypoglycemia. He was admitted, and during his hospital stay, he experienced severe hypoglycemic episodes with symptomatic presentations of diaphoresis on multiple occasions. A detailed history revealed that for diabetes, the patient had been on insulin for the first 12 years after his diagnosis, after which he was switched to metformin $500 \mathrm{mg}$ twice daily for about 2 years, and as a satisfactory glycemic control was attained, eventually metformin had also been stopped 3 years prior to the current presentation.

The patient's past medical records were obtained from the hospital at which he had been diagnosed gastrointestinal spindle cell sarcoma. Patient had not received treatment for the cancer as the disease was too widespread to be treated. The gastrointestinal spindle cell sarcoma, which had initially been surgically resected 7 years before the current presentation, had a recurrence 3 years later with abdominal and pulmonary metastasis, but no liver metastasis. No further intervention was carried out because the widely metastasized disease would not have benefited from any more surgical intervention and chemotherapy was not initiated because of the patient's comorbid illnesses.

A blood sample drawn from the patient at the time of one hypoglycemic event, revealed low serum insulin $<0.1 \mathrm{U} / \mathrm{ml}$ (normal, 2-19.6 U/ml); low C-peptide level, $0.59 \mathrm{ng} / \mathrm{ml}(0.8-3.85 \mathrm{ng} / \mathrm{ml}) ;$ low IGF-1, $16 \mathrm{ng} / \mathrm{ml}$ (5-4 ng/ml); and IGF-3, $0.9 \mathrm{ng} /$ $\mathrm{ml}(2.2-4.5 \mathrm{ng} / \mathrm{ml})$. IGF-2 levels were found to be markedly elevated at $945 \mathrm{ng} / \mathrm{ml}(47-350 \mathrm{ng} / \mathrm{ml})$. The calculated IGF-2-IGF-1 ratio was 59.06 (normal, <10), suggesting NICTH as the etiology for the patient's hypoglycemia.

The hypoglycemic episodes were initially treated with a continuous dextrose infusion followed by diazoxide treatment. However, diazoxide did not prevent his hypoglycemic episodes, so dexamethasone was considered as an alternative for his condition. The dexamethasone treatment resulted in the normalization of the patient's serum glucose levels and resolution of his symptoms. The patient was discharged in a satisfactory state few days later and followed up thereafter. No recurrence of hypoglycemic episodes was found, and he was continued on dexamethasone therapy.

\section{Discussion}

Hypoglycemia due to NICTH is rare, with a preva-

Accepted for publication May 5, 2016. Correspondence: Sorab Gupta, MD; drsorabgupta@gmail.com. Disclosures: The authors report no disclosures or conflicts of interest. JCSO 2017;15(3):e176-e177. @2017 Frontline Medical Communications. doi: https://doi.org/10.12788/jicso.0275 
lence of four times less than that of insulinoma. ${ }^{3}$ In most cases, NICTH occurs in patients with solid tumors of mesenchymal and epithelial origins such as hepatocellular carcinoma, gastric carcinoma or mesothelioma. ${ }^{4}$ In NICTH, the serum levels of insulin, C-peptide, and IGF-1 are usually decreased or undetectable. However, the circulating levels of total IGF2 may be increased, decreased, or normal. Concurrent normal to high morning cortisol and normal response to cosyntropin stimulation can rule out adrenal insufficiency and suggest NICTH. An IGF-2: IGF-1 ratio of $>10$ is considered to be clinically significant and highly suggestive of NICTH. ${ }^{5}$ Hypoglycemia in NICTH can be managed by administration of oral glucose, intravenous dextrose or glucagon. In some cases, diazoxide, a potent inhibitor of insulin secretion, has been found to be useful. ${ }^{6}$ Diazoxide directly inhibits the release of insulin through stimulation of adrenergic receptors and also has an extra pancreatic hyperglycemic effect, probably by inhibiting cyclic adenosine monophosphate phosphodiesterase, resulting in higher

\section{References}

1. Marks V, Teale JD. Tumours producing hypoglycaemia. Diabetes Metab Rev. 1991;7:79-91.

2. Dutta P, Aggarwal A, Gogate Y, Nahar U, Shah VN, Singla M. Non-islet cell tumor-induced hypoglycemia: a report of five cases and brief review of the literature. Endocrinol Diabetes Metab Case Rep. 2013;2013:130046

3. de Groot JW, Rikhof B, van Doorn J, et al. Non-islet cell tumourinduced hypoglycaemia: a review of the literature including two new cases. Endocr Relat Cancer. 2007;14:979-93.

4. Fukuda I, Hizuka N, Ishikawa Y, et al. Clinical features of insulinlike growth factor II producing non-islet-cell tumor hypoglycemia. Growth Horm IGF Res. 2006;16:211-216.

5. Marks V, Teale JD: Tumours producing hypoglycaemia. Endocr Relat Cancer. 1998;5:111-129.

6. Le Roith D. Tumor-induced hypoglycemia. N Engl J Med. plasma levels of cyclic AMP and enhanced glycogenolysis.

Glucocorticoid therapy has been shown to suppress IGF-2 in a dose dependent manner and also by increasing gluconeogenesis. ${ }^{7}$ Surgical resection of the tumor whenever possible is the treatment of choice followed by radiotherapy and chemotherapy for inoperable disease and if successful, usually results in resolution of hypoglycemia. Imatinib, is the chemotherapeutic drug of choice for metastatic GIST, but many case reports have suggested worsening of hypoglycemia in advanced GIST with the use of the drug. ${ }^{8}$ The patient described in our report was not on any chemotherapy, hence hypoglycemia could not be attributed to it. On the basis of findings among 24 patients with GIST, Rikhof and colleagues have recommended monitoring plasma levels of pro-IGF-IIE to identify patients at high risk for developing hypoglycemia, especially those with progressive disease. ${ }^{9}$ Furthermore, over expression of IGF-2 as a predictor of potential relapse may be an area for potential research and further study. ${ }^{10}$

1999;341:757-758

7. Teale JD, Marks V. Glucocorticoid therapy suppresses abnormal secretion of big IGF-II by non-islet cell tumours inducing hypoglycaemia (NICTH). Clin Endocrinol .1998;49:491-498.

8. Hamberg P, De Jong FA, Boonstra JG, et al. Non-islet-cell tumor induced hypoglycemia in patients with advanced gastrointestinal stromal tumor possibly worsened by imatinib. J Clin Oncol. 2006;24:e30-e31.

9. Rikhof B, van Doorn J, Suurmeijer AJ, et al. Insulin-like growth factors and insulin-like growth factor-binding proteins in relation to disease status and incidence of hypoglycaemia in patients with a gastrointestinal stromal tumour. Ann Oncol. 2009;20:1582-1588.

10. Braconi C, Bracci R, Bearzi I, et al. Insulin-like growth factor (IGF) 1 and 2 help to predict disease outcome in GIST patients. Ann Oncol. 2008;19:1293-1298. 